\title{
Industrial accidents triggered by natural hazards: an emerging risk issue
}

\author{
E. Krausmann ${ }^{1}$, V. Cozzani $^{2}$, E. Salzano ${ }^{3}$, and E. Renni ${ }^{1,2}$ \\ ${ }^{1}$ European Commission, Joint Research Centre, Institute for the Protection and Security of the Citizen, Via E. Fermi 2749, \\ 21027 Ispra (VA), Italy \\ ${ }^{2}$ Dipartimento di Ingegneria Chimica, Mineraria e delle Tecnologie Ambientali, Alma Mater Studiorum - University of \\ Bologna, Via Terracini 28 - 40131 Bologna, Italy \\ ${ }^{3}$ Istituto di Ricerche sulla Combustione - C.N.R., Via Diocleziano 328, 80124 Naples, Italy
}

Received: 3 February 2011 - Accepted: 2 March 2011 - Published: 24 March 2011

\begin{abstract}
The threat of natural hazards impacting chemical facilities and infrastructures with the subsequent release of hazardous substances has been recognised as an emerging risk which is likely to be exacerbated by the ongoing climate change. Within the European FP7 project iNTeg-Risk, efforts are dedicated to address the problem of Natech accidents by trying to understand their underlying causes and by developing methodologies and tools to assess Natech risk. Special attention is thereby given to the risk of chemical accidents triggered by earthquakes, floods and lightning. This work outlines the ongoing efforts in the development of new concepts and tools for Natech hazard and vulnerability ranking, risk assessment, risk-based design, and emergency planning and early warning.
\end{abstract}

\section{Introduction}

There is increasing awareness of the threat that natural hazards and disasters can pose to chemical facilities and critical infrastructures (e.g. oil and gas storage, refineries, overland oil and gas pipelines). Chemical accidents triggered by natural events, such as e.g. earthquakes, floods, lightning etc., are referred to as "Natech" accidents. All over the globe Natech accidents have occurred in the wake of natural hazards and disasters and have resulted in the release of hazardous substances leading to fatalities, injuries, environmental pollution and economic losses (e.g. Krausmann et al., 2010; Cozzani et al., 2010; Cruz and Krausmann, 2009; Steinberg and Cruz, 2004; Young et al., 2004;

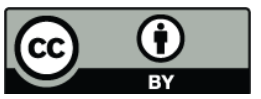

Correspondence to: E. Krausmann (elisabeth.krausmann@jrc.ec.europa.eu)
Lindell and Perry, 1997). A recent analysis of selected chemical-accident databases showed that approximately 2 $5 \%$ of the accidents with hazardous-substance releases reported in these databases were triggered by natural events (Campedel, 2008).

Natech risk differs from technological or natural risk in that its multi-hazard nature requires an integrated approach to risk management. One of the principal problems of most Natech accidents is the simultaneous occurrence of a natural disaster and a technological accident, both of which require simultaneous response efforts in a situation in which lifelines needed for disaster mitigation are likely to be unavailable. In addition, hazardous-materials releases may be triggered from single or multiple sources in one installation or at the same time from several hazardous installations in the natural disaster's impact area.

Recent studies have indicated that legislation and standards for chemical-accident prevention do not explicitly address Natech risk (Krausmann and Baranzini, 2009; Krausmann, 2010). In addition, methodologies and tools for the assessment of Natech risk are scarce, and only limited guidance for industry and the authorities on how to assess Natech risk is available. With climate change predicted to increase the frequency of severe hydro-meteorological events (Parry et al., 2007), Natech risk is expected to increase in the future. This highlights the need for the development of tools for industry and authorities to assist in the analysis of the risk in chemical installations and infrastructures due to Natech accidents.

Due to its specific nature, Natech risk was acknowledged as an emerging risk in the European 7th Framework Programme Project iNTeg-Risk. This project aims at improving the management of emerging risks related to new materials

Published by Copernicus Publications on behalf of the European Geosciences Union. 
Table 1. Technical steps in the risk management process (Mannan, 2005; CCPS, 2000; Salzano and Cozzani, 2007).

\begin{tabular}{ll}
\hline Step & Activity \\
\hline 1 & $\begin{array}{l}\text { Planning the risk management process: this involves the definition of the level of detail } \\
\text { and of the tools to be used in the analysis, so that it will be commensurate with the } \\
\text { available resources and the defined goal. }\end{array}$ \\
\hline 2 & $\begin{array}{l}\text { Hazard identification: this comprises all activities required to identify all hazards related } \\
\text { to the system under examination. }\end{array}$ \\
\hline 3 & $\begin{array}{l}\text { Qualitative risk analysis: this involves screening activities (e.g. through Key Perfor- } \\
\text { mance Indicators) aimed at identifying when and where more detailed analyses are } \\
\text { required. }\end{array}$ \\
\hline 4 & $\begin{array}{l}\text { Quantitative risk analysis: this involves quantifying both occurrence probability and } \\
\text { expected consequence magnitude of each previously identified hazard to estimate an } \\
\text { overall risk index (e.g. individual or societal risk indices, as defined e.g. in Cox, 1998). }\end{array}$ \\
\hline 5 & $\begin{array}{l}\text { Planning the mitigation measures: this requires the implementation of all the preven- } \\
\text { tion and protection measures necessary to reduce the risk level below a predetermined } \\
\text { threshold. }\end{array}$ \\
\hline 6 & $\begin{array}{l}\text { Risk monitoring and control: this comprises the activities required to avoid changes in } \\
\text { the situation examined that would increase the risk level above the acceptable threshold. }\end{array}$
\end{tabular}

and technologies to promote safety, security, environmental friendliness and social responsibility of advanced EU technologies (iNTeg-Risk, 2010). This study discusses the efforts that are underway in the frame of the iNTeg-Risk project with respect to the development of dedicated tools for Natech risk management for earthquakes, floods and lightning. This work was performed under the iNTeg-Risk Subproject 1, Task 1.5.3 D3 on "Emerging risk related to the interaction between natural hazards and technologies at community level". The results of this task fed directly into the preparation of a Handbook of Emerging risk in Subproject, and into Subproject 3 by applying the methodology for Natech risk assessment developed under T1.5.3 to case studies.

\section{Towards Natech risk management}

\subsection{A general approach to Natech risk assessment}

When developing a specific approach for Natech risk assessment, the standard risk management procedure should be adhered to, which involves the technical steps summarized in Table 1. In this general framework, both the steps of qualitative and quantitative risk analysis need to take into account the characteristics of Natech events. In particular, a dedicated approach to the characterisation of the triggering natural hazard or disaster and of the final accident scenarios is required. Therefore, the specific methodology for Natech risk analysis described in Table 2 was used in the iNTeg-Risk project (Antonioni et al., 2009).
The procedure presented in Table 2 requires a multidisciplinary effort, starting from the estimation of the occurrence probability of the natural event, (e.g. for earthquakes through Probabilistic Seismic Hazard Analysis - PSHA) and the calculation of its intensity at the industrial site, to the analysis of the equipment response behaviour to natural hazard loads and the impact of equipment damage on hazardous industrial processes.

Natural-hazard maps, historical data, and surveys are available, differing in extent, detail and quality worldwide and providing information on the natural event's likelihood and/or intensity. However, for Natech risk assessment, ideally the combination of the two parameters is required. For the purpose of this study these data were retrieved for earthquakes, floods and lightning. The intensity variables used for describing the destructive potential when interacting with industrial installations are the peak ground acceleration PGA $\left[\mathrm{m} \mathrm{s}^{-2}\right]$ for earthquakes, the maximum water height [m] and/or water speed $\left[\mathrm{m} \mathrm{s}^{-1}\right]$ for floods, and the ground flash density $N_{\mathrm{g}}\left[\mathrm{km}^{-2} \mathrm{y}^{-1}\right]$ for lightning. Although these parameters are indicative, they can usually be applied worldwide due to a satisfactory data availability. Thus, the retrieval of data on the likelihood and intensity of earthquakes, floods and lightning in any specific location is relatively straightforward.

With respect to structural analysis, only minimal requirements for the structural response of equipment subjected to natural-event loading are usually compulsory in the design phase. For earthquakes, design criteria are related to the local seismic hazard expressed in terms of the expected reference 
Table 2. Procedure used for the analysis of the risk induced by natural events in process plants.

\begin{tabular}{lll}
\hline No. & Step & Needs \\
\hline 1 & Characterization of the natural event & Frequency and severity \\
2 & Identification of target equipment & List of target equipment considered \\
3 & Identification of damage states and reference scenarios & Event trees \\
4 & Estimation of damage probability & Equipment damage models \\
5 & Consequence evaluation of the reference scenario & Consequence analysis models \\
6 & Identification of credible combinations of events & Set of event combinations \\
7 & Frequency/probability calculation for each combination & Frequencies of event combinations \\
8 & Consequence calculation for each combination & Overall vulnerability map \\
9 & Calculation of risk indices & Overall risk indices \\
\hline
\end{tabular}

seismic intensity. Moreover, active or passive prevention and mitigation systems are rarely designed to consider the additional loading from the impact of a natural hazard. This is due to the fact that the primary goals of design are the avoidance of business interruption and economic losses from possible accident initiators that are perceived to be more frequent than Natech events. Detailed structural analysis requires the application of complex methodologies, such as Finite Element Analysis or others (for details see ASCE, 1997). These tools are, however, only practicable for the analysis of simple problems or when designing new equipment. They are not easily applicable for risk analysis of large installations or industrial areas where several different equipment types have to be analysed.

\subsection{Hazard and vulnerability ranking}

The complexity of quantitative risk assessment and the corresponding need for more basic analysis approaches have led to the development of a simplified methodology for the assessment of Natech risk within the iNTeg-Risk project. This methodology is based on the definition of hazard indices for natural and technological events and a corresponding ranking of the equipment vulnerability. A ranking of the equipment vulnerability to natural events could be useful for designing and planning prevention and mitigation measures and systems. Moreover, the ranking provides a simplified risk assessment tool that can be used in most situations instead of complex assessment techniques. To this end, a four-level hazard index scale was defined as shown in the first two columns of Table 3. The natural-hazard classification for earthquakes and lightning in any specific location are also presented in Table 3. Flood-related analyses are more complex, though conceptually similar, and will not be discussed here for the sake of brevity.

A similar approach was adopted for the vulnerability ranking of typical industrial equipment found in process plants or storage sites. As a first step, critical equipment categories and their associated four-level hazard index under naturalevent loading were determined, based on the extent of dam-
Table 3. Seismic hazard classification adopted by the Global Seismic Hazard Assessment Program (ESPON, 2006) and lightning hazard classification in terms of annual frequency per square kilometre $\left(N_{\mathrm{g}}\right)$.

\begin{tabular}{llcc}
\hline $\begin{array}{l}\text { Hazard } \\
\text { index }\end{array}$ & $\begin{array}{l}\text { Hazard } \\
\text { classification }\end{array}$ & $\begin{array}{c}\text { PGA range }\left[\mathrm{m} \mathrm{s}^{-12}\right] \\
\text { (50-yr exceedance } \\
\text { probability })\end{array}$ & $\begin{array}{c}N_{\mathrm{g}}(I>3 \mathrm{kA}) \\
{\left[\mathrm{km}^{-2} \mathrm{y}^{-1}\right]}\end{array}$ \\
\hline 1 & Very low & $\leq 0.8$ & $<0.25$ \\
2 & Low & $0.8-2.4$ & $0.25-2$ \\
3 & Moderate & $2.4-4.0$ & $2-8$ \\
4 & High & $>4.0$ & $>8$ \\
\hline
\end{tabular}

age of an equipment item, its operating conditions and the hazard posed by the released substance. This was based on an extensive analysis of Natech accidents, as well as on a review of the technical literature (Campedel et al., 2008; Fabbrocino et al., 2005; Salzano et al., 2003; Seligson et al., 1996; Talaslidis et al., 2004). The results of the analysis for earthquakes and lightning are shown in Table 4.

Using the above natural-hazard and technological-hazard classifications, vulnerability analyses for industrial equipment under natural-event loading can be performed and the risk from possible damage can be estimated. To this end, a number of discrete limit states for structural damage to equipment (damage state, DS) were defined which ranged from the total absence of damage (DS1) to total collapse of the structure (DS3) (Salzano and Cozzani, 2007). In order to obtain a measure of the quantity and rate of hazardoussubstance releases from damaged equipment due to a specific natural-hazard impact, three risk states (RS) were defined in the iNTeg-Risk project which are a function of an equipment's damage state and the type of equipment affected (e.g. pressurised or at atmospheric pressure). Each risk state can then be associated with a specific accident scenario (toxic dispersion, fire, explosion). The three risk states are (Salzano and Cozzani, 2007): 
Table 4. Critical equipment and associated technological hazard index for events triggered by earthquakes and lightning (in italic).

\begin{tabular}{lccccc}
\hline $\begin{array}{l}\text { Equipment } \\
\text { category }\end{array}$ & Liquid & $\begin{array}{c}\text { Cryogenic } \\
\text { liquid }\end{array}$ & $\begin{array}{c}\text { Evaporating } \\
\text { liquid }\end{array}$ & $\begin{array}{c}\text { Liquefied } \\
\text { gas }\end{array}$ & Gas \\
\hline Vessels & $1 / 4$ & $2 / 4$ & $3 / 4$ & $4 / 4$ & $3 / 3$ \\
Piping & $1 / 3$ & $2 / 2$ & $3 / 3$ & $4 / 4$ & $2 / 2$ \\
Columns & $1 / 2$ & $2 / 2$ & $2 / 2$ & $3 / 4$ & $2 / 1$ \\
Reactors and heat exchangers & $1 / 2$ & $2 / 2$ & $2 / 2$ & $3 / 3$ & $1 / 1$ \\
\hline
\end{tabular}

- RS1: continuous release from a hole with an equivalent diameter of $10 \mathrm{~mm}$;

- RS2: continuous release of the complete inventory (in more than $10 \mathrm{~min}$ );

- RS3: instantaneous release of the complete inventory (in less than $2 \mathrm{~min}$ ) following severe structural damage.

Equipment vulnerability can then be calculated by correlating the natural-hazard trigger intensity with the probability of a given risk state. This is achieved by defining an equipment fragility function $F_{\text {equipment }}$ which expresses the probability of structural failure leading to a loss of containment of a given severity. Using this fragility function, the Natech vulnerability function $P_{\text {nat }}$ for a given natural event "nat" follows:

$P_{\text {nat }}=F_{\text {equipment }}\left[\mathrm{RS} \mid \alpha_{\text {nat }}\right] \cap H_{\text {nat }}\left[\lambda_{\text {nat }}, T\right]$,

where $\alpha_{\text {nat }}$ is the specific value of the severity parameter $\lambda_{\text {nat }}$ that characterises a natural event, and $H_{\text {nat }}$ is the occurrence probability of a specific $\lambda_{\text {nat }} . P_{\text {nat }}$ is therefore the total equipment failure probability of specific equipment with hazardous-substance release corresponding to risk state RS due to the impact of a natural event. It considers all possible values of $\lambda_{\text {nat }}$ combined with the associated $H_{\text {nat }}$ over a given time period $T$, which can, for instance, be the Technical Service Life (TSL) of an equipment item. Equation (1) can be simplified by introducing a univocal threshold values for the natural-hazard intensity $\lambda_{\text {nat, thresh }}$ for a specific risk state RS, and by rearranging Eq. (1) we obtain:

$$
P_{\text {nat }, \mathrm{RS}}=F_{\text {equipment }}\left(\mathrm{RS} \mid \lambda_{\text {nat, thresh, RS }}\right) \cdot H_{\text {nat }}\left(\lambda_{\text {thresh }, \mathrm{RS}}, T\right)(2)
$$

Summation over all RS values in Eq. (2) yields the Natech vulnerability function for all possible risk states as function of a specific natural event. $P_{\text {nat }}$ can be used for the vulnerability ranking of industrial equipment if reference probabilities are available.

A classification of the Natech risk is then obtained by creating a risk matrix that combines the probability of loss of containment $P_{\text {nat }}$ with the associated consequences. Table 5 provides an example of a risk matrix typically used in technological risk assessment. A detailed description of the equipment vulnerability ranking and its results for earthquakes, floods and lightning within the iNTeg-Risk project is provided in Salzano et al. (2010).

\subsection{Quantitative risk assessment}

The quantitative assessment of the risk due to Natech accidents is of crucial importance in order to understand the relevance of these events for industrial safety. A well-accepted framework procedure is available for the quantitative assessment of industrial risk, and several specific tools for its practical implementation exist (e.g. the Purple Book approach (Uijt de Haag and Ale, 1999), the bow-tie approach proposed by ARAMIS (Delvosalle et al., 2004), etc.). However, because of the multi-hazard nature of Natech risk, the conventional Quantitative Risk Assessment (QRA) procedure needs to be extended to take into account the characteristics of Natech accident scenarios. The general process developed for the assessment of Natech risk was outlined in Table 2 (Antonioni et al., 2009). While this process includes only a limited number of Natech-specific steps, dedicated models and tools are required to extend the conventional QRA procedure to Natech risk assessment. These are:

- specific damage models to estimate the extent and probability of equipment damage caused by a natural event;

- a specific procedure to account for the possibility of simultaneous releases from more than a single process or storage unit.

The starting point of the quantitative Natech risk assessment methodology is the characterisation of the natural haz$\operatorname{ard}(\mathrm{s})$ at the site where the hazardous industrial facility is located (Step 1 in Table 2). The frequency and magnitude of the natural event need to be characterised by a sufficiently simple approach, such as the one presented in Sect. 2.2., which is suitable for use in a risk assessment framework. A limited number of "reference events" may be defined, each having a given intensity and an expected frequency or time of return. These parameters can be aggregated into an impact vector that can be used for simplified damage analysis. It should be noted that this step is neither intended to provide a detailed characterisation of the natural hazard at the site, nor to provide data for a detailed structural analysis of the damage to structures. The purpose is only to obtain the input 
Table 5. An example of a risk matrix (adapted from Cox, 1998). The red colour denotes areas of intolerable risk, the orange and the yellow cells indicate areas where risk reduction measures should be implemented, and the green colour shows areas where risk is broadly acceptable.

\begin{tabular}{|c|c|c|c|c|c|}
\hline \multirow[t]{2}{*}{ Frequency } & \multicolumn{5}{|c|}{ Consequence } \\
\hline & Very low & Low & Moderate & High & Very high \\
\hline \multicolumn{6}{|l|}{ Likely } \\
\hline \multicolumn{6}{|l|}{$\left(>0.1 \mathrm{yr}^{-1}\right)$} \\
\hline \multicolumn{6}{|l|}{ Possible } \\
\hline \multicolumn{6}{|l|}{$\left(10^{-1}-10^{-2} \mathrm{yr}^{-1}\right)$} \\
\hline \multicolumn{6}{|l|}{ Unlikely } \\
\hline \multicolumn{6}{|l|}{$\left(10^{-2}-10^{-3} \mathrm{yr}^{-1}\right)$} \\
\hline \multicolumn{6}{|l|}{ Very unlikely } \\
\hline \multicolumn{6}{|l|}{$\left(10^{-3}-10^{-4} \mathrm{yr}^{-1}\right)$} \\
\hline \multicolumn{6}{|l|}{ Remote } \\
\hline$\left(<10^{-4} \mathrm{yr}^{-1}\right)$ & & & & & \\
\hline
\end{tabular}

data necessary for the use of simplified equipment damage models.

Once the target equipment has been identified, the possible damage states have to be associated to it (Steps 2-3). The damage states are then used to calculate the expected severity of the loss of containment. Once this information is available, event trees including existing safety barriers are applied to identify the final outcomes of the reference scenarios associated to a specific damage mode. Specific event trees derived from the analysis of past Natech accidents are required to take into account the features of post-release scenarios in Natech events (Cozzani et al., 2010; Renni et al., 2010a).

Simplified equipment damage models suitable for use within a QRA framework are a prerequisite for applying the quantitative approach presented in Table 2 (Step 4). Empirical equipment damage models were developed or are under development, partly based on the analysis of past accident data (Salzano et al., 2003; Campedel et al., 2008; Antonioni et al., 2009; Renni et al., 2010b). Nevertheless, further work is needed on this topic to extend and validate the available models.

The consequence analysis for the final outcomes of the reference scenarios can be carried out using conventional models (Step 5). However, for Natech accidents there is a high likelihood that more than one reference scenario may take place simultaneously due to damage to more than one process or storage unit. This is taken into account by (i) identifying the credible combinations of final outcomes, (ii) calculating the frequency for each combination, and (iii) deter- mining the consequences for each credible combination of final outcomes (Steps 6-8). As a final step, an estimation of the accompanying risk can be provided, usually in the form of Individual Risk curves or Societal Risk (F-N curves). A description of the definition and calculation of these risk indices is provided in Cox (1998).

The above procedure was applied to several test cases to understand the applicability of the developed procedure and to estimate the magnitude of the risk due to natural-hazard impact. Figure 1 shows the individual risk curves calculated with the described methodology for a storage tank farm of an oil refinery. More specifically, the individual risk was calculated considering accident scenarios due to the earthquaketriggered release of flammable substances and the ensuing fires. The possible presence of multiple fires simultaneously triggered by an earthquake was taken into account in the calculations. Figure 2 presents the results obtained for the calculation of the societal risk for the same case study. Not surprisingly, the inclusion of the earthquake impact in the risk calculation yielded a significant increase of the societal risk. Further details on the assessment procedure used and the assumptions made are reported in Antonioni et al. (2009) and Campedel et al. (2008). The obtained results demonstrate that Natech risk characterisation by extending QRA is a promising route for quantifying the importance of the contribution of Natech scenarios to overall industrial risk. 

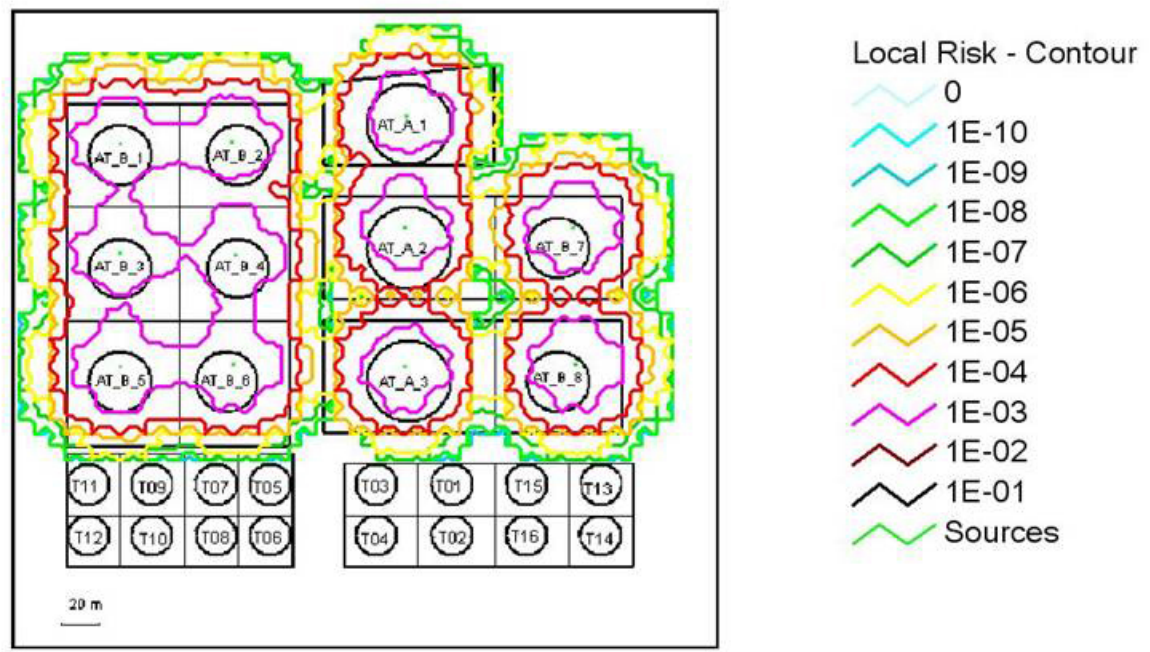

Fig. 1. Individual risk curves calculated for earthquake-induced loss-of-containment events in a storage tank farm of an oil refinery.

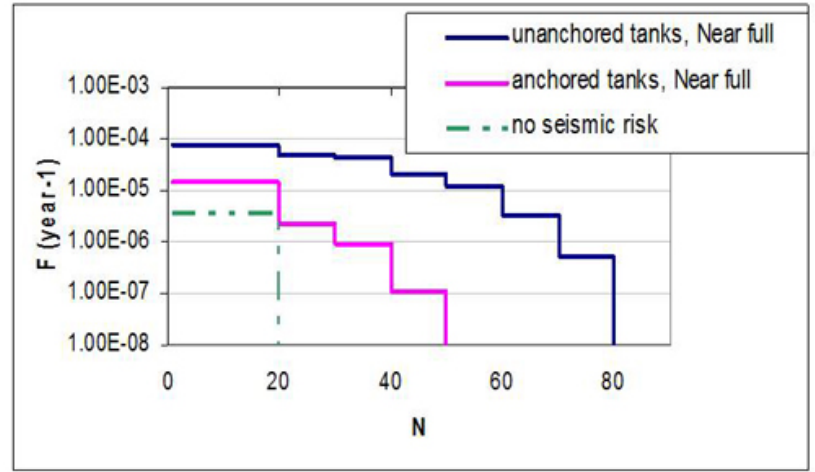

Fig. 2. Societal risk calculated for a storage tank farm with (dashed line) and without (solid lines) considering loss-of-containment events triggered by earthquakes.

\subsection{Risk-based design}

The challenge of preventing Natech accidents calls for new tools that supplement the current approaches to the design of industrial installations which are predominantly deterministic. Conventionally, for Natech accident prevention equivalent static loads from a natural event with a given reference intensity (e.g. a certain PGA or water height) are calculated, and the facility and its components are then designed to withstand such an event. The resilience of structures thus obtained should prevent building collapse and thereby guarantee life safety as the most important goal. However, the reduction of Natech risk necessitates not only the preservation of structural integrity but also the avoidance of loss of containment of hazardous substances. Unfortunately, the specific requirements for process equipment are not always recognised, which can lead to the application of generic and therefore possibly inadequate design criteria with respect to natural-event loading.

Risk-based design can complement the deterministic design approach when dealing with little-known hazards or changing boundary conditions. In the specific case of Natech risk, critical equipment items are identified in a first step, as not all equipment is equally vulnerable to a natural-hazard impact. This can be achieved by an in-depth analysis of Natech accidents reported in industrial accident databases. Figure 3 provides an example of the main equipment types found to be involved in lightning-triggered accidents reported in selected accident databases. The findings from the analysis of Natech accidents triggered by earthquakes, floods and lightning are discussed in detail in Krausmann et al. (2011), Cozzani et al. (2010) and Renni et al. (2010a). Considering the residual functionality requirements for the critical equipment (prevention of structural damage and loss of containment) and taking into account the tolerable risk of failure, the additional loads on the equipment from a natural event are assessed. This provides a more realistic assessment of design loads than applying generic design criteria. Application of the risk-based approach necessitates, however, further methodological development for Natech hazard assessment.

\subsection{Emergency planning}

Natech accidents pose a particular challenge to emergency planning as they require response to a chemical accident with possibly multiple and simultaneous hazardous-substance releases when emergency response personnel is busy dealing with the consequences of the natural disaster. Moreover, lifelines (water, power) may not be available for fighting the accident, as they may have been downed by the natural disaster. 
Table 6. Characteristics and effectiveness of a Natech-specific early-warning system as function of $t_{\mathrm{warn}} / t_{\mathrm{act}}$.

\begin{tabular}{lll}
\hline$t_{\mathrm{warn}} / t_{\mathrm{act}}$ & Characteristics & Effectiveness \\
\hline$\ll 1$ & $\begin{array}{l}\text { Short warning time or slow } \\
\text { preventive/mitigative action }\end{array}$ & $\begin{array}{l}\text { Low. Little time to implement actions } \\
\text { to prevent or mitigate an accident. }\end{array}$ \\
\hline$\approx 1$ & $\begin{array}{l}\text { Warning time similar to time for } \\
\text { preventive/mitigative action }\end{array}$ & $\begin{array}{l}\text { Medium. Some preventive actions } \\
\text { possible prior to striking of the natural } \\
\text { event. }\end{array}$ \\
\hline$\gg 1$ & $\begin{array}{l}\text { Long warning time or fast } \\
\text { preventive/mitigative action }\end{array}$ & $\begin{array}{l}\text { High. Sufficient time for the implemen- } \\
\text { tation of preventive or mitigating ac- } \\
\text { tions, even if they are time-consuming. }\end{array}$ \\
\hline
\end{tabular}

Other mitigation measures, such as e.g. catch basins, water deluges etc. may also have failed due to the natural event. Steinberg and Cruz (2004) provide a graphic description of this problem during the 1999 Kocaeli earthquake in Turkey.

This indicates that emergency planning that considers the characteristics of Natech accidents is required, as otherwise it may be difficult if not impossible, to mitigate the consequences of such an accident. Consequently, plant-internal emergency plans should take this into account and provide e.g. for backup lifelines or specific emergency procedures to cope with the consequences of a Natech event. In order to be conservative, accident scenarios used for emergency planning should be based on the assumption that available safety barriers have failed. In addition, for communities in the vicinity of hazardous facilities or infrastructures situated in natural-hazard prone areas, disaster management plans need to be drawn up that incorporate the evacuation of residents in view of a natural-hazard impact on the facility and the hazardous-substance releases potentially triggered by it. Particular attention should be devoted to the possible impact of releases of toxic or flammable substances on the rescue operations. An assessment of the vulnerability of the emergency resources themselves is also called for.

\subsection{Early warning}

Early-warning systems play a pivotal role in the reduction of natural-disaster risk. Less common is the availability and use of early warning when it comes to the prevention of chemical accidents from natural events or the mitigation of their consequences. This is partly due to the very short warning times for some natural hazards, which do not allow effective measures to be implemented in the time available for preventive action. Another cause may be a lack of awareness of Natech risk that may have hitherto hampered the development of early-warning systems for specific use in Natech accident prevention and mitigation.

The purpose of early warning for chemical facilities or transmission pipelines is the avoidance of natural-event triggered damage to and releases from critical equipment items

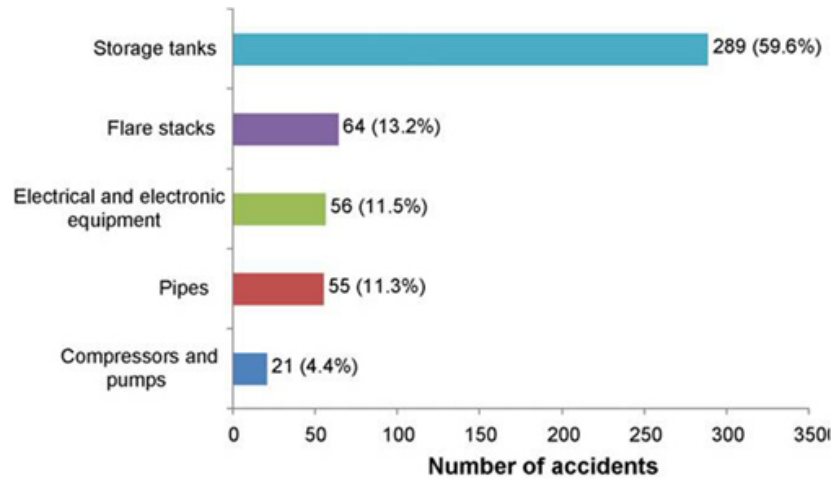

Fig. 3. Main equipment types involved in lightning-triggered Natech accidents (analysis based on 485 accidents) (Renni et al., 2010a).

that are used in the processing, transport or storage of hazardous substances. From an operator point of view, this can be achieved by receiving timely warning of an imminent natural hazard from the authorities or by installing a sensor network (e.g. for earthquakes) on site, as well as the rapid evaluation of the signals from the sensors. Safety interlock systems and fast shut-off valves for dangerous processes complement the system and act synergistically to prevent an accident or mitigate its consequences. It has to be noted, though, that the natural event may not only impact critical equipment but it may also affect the very safety systems designed to protect the facility.

The effectiveness of an early-warning system for Natech accidents is characterised by the ratio of the warning time, $t_{\text {warn }}$, and the time necessary for the required preventive or mitigative action, $t_{\text {act }}$ (Salzano et al., 2009). While $t_{\text {warn }}$ does not depend on the type of equipment at risk, $t_{\text {act }}$ is a strong function of the equipment, the substances it contains, its operating conditions, and associated actions of people and systems. Table 6 shows the effectiveness of the early-warning system based on the ratio of warning and action time. 
For earthquakes, warning times range from a few seconds to a few minutes, depending on the distance of the chemical facility from the earthquake epicentre. This does not leave much time for the implementation of protection measures. In this case, the actuation of automatic valve closure or emergency shutdown upon activation of the sensor net would be most effective as human intervention is probably not fast enough. However, typical times for safety valve isolation for equipment at atmospheric pressure (e.g. fuel storage tanks) is 10 minutes, and about $3 \mathrm{~min}$ for pressurised equipment (van den Bosch and Weterings, 1997). Minor or severe equipment damage and releases, depending on the earthquake intensity, are therefore possible. Warning times for floods are much higher and may range from hours to days which leaves room for preventive or mitigation action. If $t_{\mathrm{warn}}>t_{\mathrm{act}}$, measures such as plant shut-down, depressurisation of equipment, or the transfer of hazardous substances from equipment in areas that will be flooded to safe locations can be envisaged. The high cost associated with these actions requires the earlywarning system to be resistant to false alarms. In the case of lightning, there is little benefit from early warning as the only information available would be weather forecasts indicating the possible increase in lightning strike density in coarse spatial resolution.

\section{Conclusions}

Natech accidents have been recognised as an emerging risk in the chemical and process industries. A survey of industrial accident databases showed that up to $5 \%$ of industrial accidents were triggered by natural events which impact industrial facilities that process or store hazardous substances. The work carried out within the iNTeg-Risk project allowed the framing of the challenges posed by the risk management of Natech scenarios. The developed methodologies for risk appraisal and characterisation provided a new approach for the ranking and the quantitative assessment of Natech risk. These methodologies will also contribute to addressing other key issues related to the management of Natech risk, such as risk-based design, emergency planning and early warning.

Acknowledgements. This work was funded by and performed under the 7th Framework Programme Integrated Project iNTegRisk (CP-IP 213345-2). The project seeks to improve early recognition and monitoring of emerging risks, to reduce accidents caused by them, and to decrease reaction times if major accidents involving emerging risks occur. The iNTeg-Risk project is divided into 5 main sub-projects and has a duration of 4.5 years. In order to achieve its goals, the project identifies specific emerging risks from case studies, develops solutions for the identified risks, validates the solutions and disseminates them through the "iNTeg-Risk one-stop-shop. The project website is available at http://www.integrisk.eu-vri.eu/.

Edited by: E. Petrova

Reviewed by: M. Hailwood and another anonymous referee

\section{References}

Antonioni, G., Bonvicini, S., Spadoni, G., and Cozzani, V.: Development of a general framework for the risk assessment of Natech accidents, Rel. Eng. Safety Sys., 94, 1442-1450, 2009.

API 650: Welded Steel Tanks for Oil Storage, 8th Edition, American Petroleum Institute, 2003.

ASCE: American Society of Civil Engineers, Guidelines for seismic evaluation and design of petrochemical facilities, Task Committee on seismic evaluation and design of petrochemical facilities of the Petrochemical Committee, Reston (Virginia), 1997.

Campedel, M.: Analysis of major industrial accidents triggered by natural events reported in the principal available chemical accident databases, Report EUR 23391 EN, 2008.

Campedel, M., Cozzani, V., Garcia-Agreda, A., and Salzano E.: Extending the Quantitative Assessment of Industrial Risks to Earthquake Effects, Risk Anal., 28/5, 1231-1246, 2008.

CCPS: Guidelines for chemical process quantitative risk analysis, 2nd Ed., Center for Chemical Process Safety/AIChE, New York, 2000 .

Cox, T.: Risk integration and decision-making, in: Risk assessment and management in the context of the Seveso II Directive, edited by: Kirchsteiger, C., Christou, M. D., and Papadakis, G. A., Industrial Safety Series, Vol. 6, Elsevier, 1998.

Cozzani, V., Campedel, M., Renni, E., and Krausmann, E.: Industrial accidents triggered by flood events: analysis of past accidents, J. Haz. Mat., 175, 501-509, 2010.

Cruz, A. M. and Krausmann, E.: Hazardous-materials releases from offshore oil and gas facilities and emergency response following Hurricanes Katrina and Rita, J. Loss Prev. Proc. Ind., 22, 59-65, 2009.

Delvosalle, C., Fievez, C., and Pipart, A.: ARAMIS: Accidental Risk Assessment Methodology for Industries in the Context of the Seveso II Directive, ARAMIS project Deliverable D.1.C., July 2004.

ESPON: European Spatial Observation Network, Project 1.3.1. The spatial effects and management of natural and technological hazards in general and in relation to climate change, 2006.

Fabbrocino, G., Iervolino, I., Orlando, F., and Salzano, E.: Quantitative risk analysis of oil storage facilities in seismic areas, J. Haz. Mat., 12, 361-369, 2005.

iNTeg-Risk: Early Recognition, Monitoring and Integrated Management of Emerging, New Technology Related, Risks, available at: http://www.integrisk.eu-vri.eu/, last access: December 2010.

Krausmann, E.: Analysis of Natech risk reduction in EU Member States using a questionnaire survey, Report EUR 24661 EN, 2010.

Krausmann, E. and Baranzini, D.: Natech risk reduction in OECD Member Countries: Results of a questionnaire survey, Report JRC 54120, European Communities, 2009.

Krausmann, E., Cruz, A. M., and Affeltranger, B.: The impact of the 12 May 2008 Wenchuan earthquake on industrial facilities, J. Loss Prev. Proc. Ind., 23, 242-248, 2010.

Krausmann, E., Renni, E., Campedel, M., and Cozzani, V.: Industrial accidents triggered by earthquakes, floods and lightning: lessons learned from a database analysis, Nat. Haz., doi:10.1007/s11069-011-9754-3, 2011.

Lindell, M. K. and Perry, R. W.: Hazardous materials releases in the Northridge earthquake: implications for seismic risk assessment, Risk Anal., 17(2), 147-156, 1997. 
Mannan, S. (Ed.): Lees' loss prevention in the process industries, 3rd ed., Elsevier Butterworth Heinemann, Oxford, 2005.

Parry, M. L., Canziani, O. F., Palutikof, J. P., van der Linden, P. J., and Hanson, C. E. (Eds.): Contribution of Working Group II to the 4th Assessment Report of the Intergovernmental Panel on Climate Change, Cambridge University Press, 2007.

Renni, E., Krausmann, E., and Cozzani, V.: Industrial accidents triggered by lightning, J. Haz. Mat., 184, 42-48, 2010a.

Renni, E., Cozzani, V., Krausmann, E., Borghetti, A., Paolone, M., and Nucci, C.A.: An approach to the quantitative assessment of risk due to major accidents triggered by lightning, In: Proc. 13th Int. Symposium on Loss Prevention and Safety Promotion in the Process Industries, 6-9 June 2010, Bruges, Belgium, 2010b.

Salzano, E. and Cozzani, V.: Quantitative risk assessment of industrial processes: The path towards a global approach, In: Focus on Hazardous Materials Research, edited by: Mason, L. G., Nova Science Publishers, New York, 2007.

Salzano, E, Iervolino, I., and Fabbrocino G.: Seismic risk of atmospheric storage tanks in the framework of quantitative risk analysis, J. Loss Prev. Proc. Ind., 16, 403-409, 2003.

Salzano, E., Garcia Agreda, A., Di Carluccio, B., and Fabbrocino, G.: Risk assessment and early warning systems for industrial facilities in seismic zones, Rel. Eng. Syst. Safety, 94, 1577-1584, 2009.

Salzano, E., Rota, R., Busini, V., Derudi, M., Masi, M., Marzo, E., Moscatelli, D., Nano, G., Cozzani, V., Spadoni, G., Antonioni, G., Bonvicini, S., Stramigioli, C., and Santarelli, F.: Methodological issues: screening of vulnerability and analysis of Natech accidental risk, iNTeg-Risk Project Report ERRA D3, 2010.
Seligson, H. A., Eguchi, R. T., Tierney, K. J., and Richmond, K.: Chemical Hazards, mitigation and preparedness in areas of high seismic risk; a methodology for estimating the risk of postearthquake hazardous materials release, Technical Report NCEER-96-0013, National Center for Earthquake Engineering Research, State University of NY at Buffalo, 1996.

Steinberg, L. J and Cruz, A. M.: When natural and technological disasters collide: lessons from the Turkey earthquake of August 17, 1999, Nat. Haz. Rev., 5(3), 121-130, 2004.

Talaslidis, D. G., Manolis, G. D., Paraskevopoulos, E., Panagiotopoulos, C., Pelekasis, N., and Tsamopoulos, J. A.: Risk analysis of industrial structures under extreme transient loads, Soil Dyn. Earthqu. Eng., 24, 435-448, 2004.

Uijt de Haag, P. A. M. and Ale, B. J. M.: Guidelines for quantitative risk assessment (Purple Book), CPR 18E, Committee for the Prevention of Disasters, The Hague, The Netherlands, 1999.

van den Bosch, C. J. H. and Weterings, R. A. P. M.: Methods for the calculation of physical effects (Yellow Book), CPR 14E, Committee for the Prevention of Disasters, The Hague, The Netherlands, 1997.

Young, S., Balluz, L., and Malilay, J.: Natural and technologic hazardous material release during and after natural disaster: a review, Sci. Total Environ., 322, 3-20, 2004. 